\title{
Endocardite por Escherichia Coli: \\ Quando o Improvável Acontece
}

\section{Endocarditis by Escherichia Coli: When the Unlikely Happens}

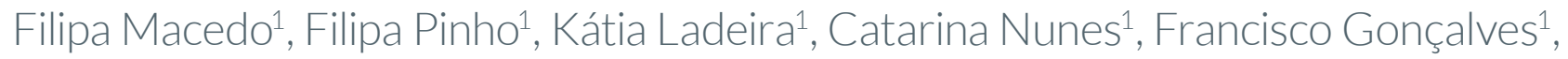
Luísa Pinto ${ }^{1}$, Carlos Capela ${ }^{1}$

\section{RESUMO}

Homem, 88 anos, recorre à urgência por astenia generalizada, anorexia e diminuição do débito urinário. Estava febril, hipotenso e com auscultação cardiopulmonar normal. Analiticamente apresentava leucocitose, creatinina de 3,1 mg/dL e leucocitúria. $\bigcirc$ doente foi internado por lesão renal aguda e medicado com ciprofloxacina assumindo uma infeção urinária. Foi isolada uma Escherichia coli na urocultura e 2 amostras de hemoculturas e o antibiótico foi alterado para meropenem de acordo com o antibiograma. Pela febre persistente e aumento dos parâmetros inflamatórios, foi realizado ecocardiograma transtorácico ao dia 14 de internamento, que revelou uma vegetação na válvula mitral, tendo-se adicionado à antibioterapia a gentamicina e vancomicina. Um acidente vascular cerebral isquémico, com transformação hemorrágica e plegia esquerda, e uma perfuração severa da válvula mitral posterior, complicaram o curso clínico. O estado clínico gradualmente melhorou e o doente transitou para uma unidade de reabilitação ao fim de 59 dias de internamento.

Este caso pretende exemplificar como a endocardite é ainda uma entidade muitas vezes de difícil diagnóstico associada a complicações graves e obrigando a internamento prolongado.

PALAVRAS-CHAVE: Endocardite; Escherichia Coli; Infeções por Escherichia Coli; Infeções Urinárias 


\begin{abstract}
An 88-year-old male presented with tiredness, diminution of urinary debit and anorexia. The patient was febrile, hypotensive and cardiopulmonary auscultation was normal. Blood-analysis revealed leukocytosis and creatinine $3.1 \mathrm{mg} / \mathrm{dL}$. Urinalysis indicated leukocyturia. The patient was medicated with ciprofloxacin assuming a urinary infection. An Escherichia coli was isolated in urine-microbiology and in 2 samples of blood-culture and antibiotic was changed to meropenem based on antibiogram. Due to constant fever and high inflammatory parameters, an echocardiogram was performed and showed vegetation in mitral valve, so vancomicin and gentamicin were addicted to treatment. Ischemic stroke, with hemorrhagic transformation and left plegia, and a severe perforation of the posterior mitral valve, complicated the clinical course. The overall clinical status gradually improved. A rehabilitation program was set and the patient moved to a rehabilitation unit after 59 days of hospitalization.

This case aims to illustrate how endocarditis is still an entity often difficult to diagnose and is associated with severe complications and requiring prolonged hospitalization.
\end{abstract}

KEYWORDS: Endocarditis; Escherichia Coli; Escherichia Coli Infections; Urinary Tract Infections

\section{INTRODUÇÃO}

A endocardite consiste na inflamação ou infeção do endocárdio e comummente afeta as válvulas cardíacas. ${ }^{1}$ A endocardite infeciosa é uma doença incomum e quando causada por micro-organismos Gram-negativos é ainda mais rara. A Escherichia coli (E. coli) é a causa mais comum de infeções do trato urinário e de septicemia por Gram-negativos. Raramente envolve o endocárdio. ${ }^{2}$

Os autores apresentam o caso de um doente internado por infeção do trato urinário que, pela evolução desfavorável e imprevisível, obrigou a estudo complementar, chegando-se ao diagnóstico de endocardite da válvula mitral por E. coli.

\section{DESCRIÇÃO DO CASO}

Um doente do sexo masculino, 88 anos de idade, autónomo, com antecedentes de hipertensão arterial e insuficiência cardíaca previamente medicado, recorreu ao serviço de urgência por apresentar desde há 3 dias astenia generalizada, anorexia e noção de diminuição do débito urinário. Ao exame objetivo, salienta-se febre de $38,4^{\circ} \mathrm{C}$, hipotensão de $86 / 42$ mmHg embora normocárdico. Auscultação cardiopulmonar e abdómen sem alterações. A radiografia pulmonar era normal e no eletrocardiograma apresentava-se em ritmo sinusal. Nas análises sanguíneas de realçar uma leucocitose, trombocitopenia, proteína C reativa (PCR) elevada, creatinina aumentada e ionograma alterado (Tabela 1). Na análise de urina apenas leucocitúria (Tabela 2).

É admitido no serviço de medicina interna por infeção do trato urinário e lesão renal aguda de etiologia multifatorial, iniciando antibioterapia com ciprofloxacina.
TABELA 1. Estudo analítico realizado em âmbito de urgência.

\begin{tabular}{|c|c|c|}
\hline \multicolumn{3}{|c|}{ Análises Sanguíneas } \\
\hline & Valor & Valor de referência \\
\hline Ureia & $150 \mathrm{mg} / \mathrm{dL}$ & $15-39$ \\
\hline Creatinina & $3,1 \mathrm{mg} / \mathrm{dL}$ & $0,70-1,20$ \\
\hline Ionograma: K+ & $5,7 \mathrm{mmol} / \mathrm{L}$ & $3,5-5,1$ \\
\hline $\mathrm{Na}+$ & $127 \mathrm{mmol} / \mathrm{L}$ & $136-145$ \\
\hline $\mathrm{Cl}$ & $93 \mathrm{mmol} / \mathrm{L}$ & $98-107$ \\
\hline PCR & $194 \mathrm{mg} / \mathrm{L}$ & $<3,0$ \\
\hline Pró-BNP & 10346 pg/mL & $<450$ \\
\hline $\mathrm{Hb}$ & $12,6 \mathrm{~g} / \mathrm{dL}$ & $13,5-17,0$ \\
\hline Leucócitos & $25400 \times 10^{3} / \mathrm{uL}$ & $4,0-11,0$ \\
\hline Plaquetas & $123 \times 10^{3} / \mathrm{uL}$ & $150-400$ \\
\hline
\end{tabular}

TABELA 2. Estudo urinário realizado em âmbito de urgência.

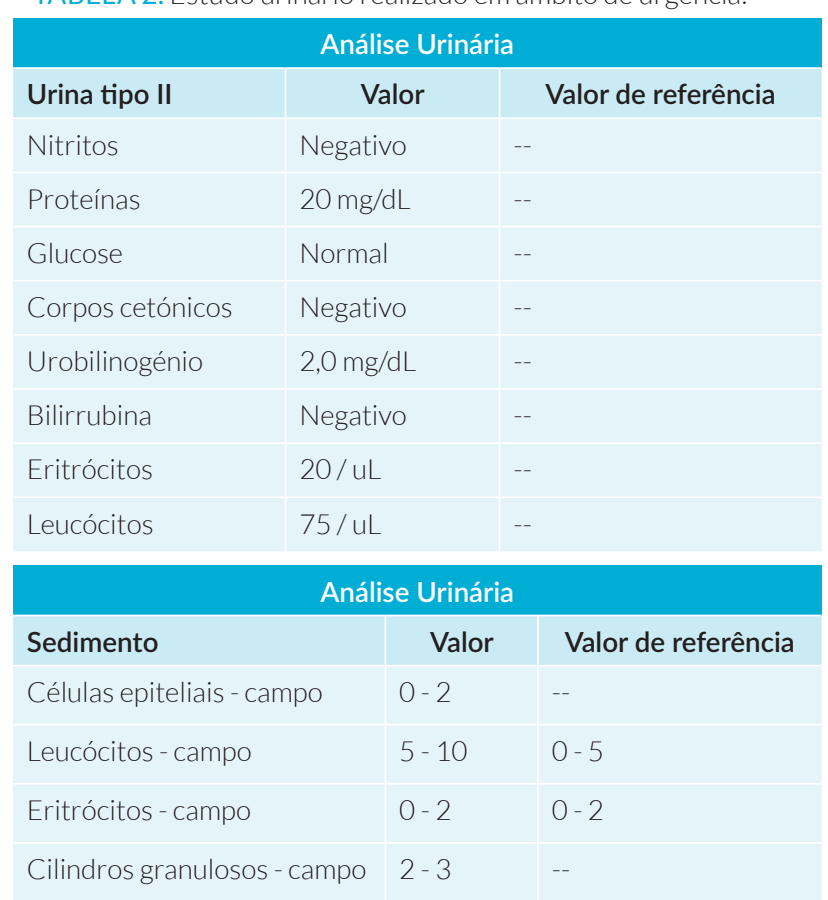


Durante 5 dias o doente obteve uma resposta clínica e laboratorial favorável, com melhoria sintomática, diminuição dos parâmetros inflamatórios, apirexia sustentada e creatinina a diminuir.

Ao sexto dia de internamento, o doente ficou prostrado e fez um pico febril. Na urocultura e em 2 amostras de hemoculturas (em aerobiose) colhidas no serviço de urgência foi isolada uma E. coli apenas sensível às cefalosporinas e ao meropenem, pelo que se opta escalar antibioterapia para meropenem. Ao $12^{\circ}$ dia de internamento (sexto dia de antibioterapia com meropenem) apresentou novo pico febril associado a quadro de desorientação. Visto que o doente apresentava persistentemente PCR elevada e leucocitose (Tabela 3), adicionou-se tigeciclina ajustada à função renal.

Por manutenção de febre diária e aparecimento de sopro sistólico de novo, realizou ecocardiograma transtorácico ao $14^{\circ}$ dia de internamento, que mostrou massas apensas à face auricular do folheto posterior da válvula mitral, a maior com cerca de 23 × 25 mm e outra com cerca de 11 mm, compatíveis com vegetações. Ajustou-se então antibioterapia para vancomicina, gentamicina e meropenem por endocardite secundária a sépsis por E. coli.

Ao $19^{\circ}$ dia de internamento, o doente apresentou hemiparesia esquerda de novo, pelo que foi pedida tomografia computorizada (TC) de crânio que mostrou um enfarte parietal direito cortico-subcortical com componente hemorrágico (Fig. 1). Avaliado também por neurologia não havendo medidas terapêuticas adicionais a propor de momento. Manteve enoxaparina profilática. Repetiu TC de crânio 3 dias depois para controlo da reabsorção da hemorragia, exame que mostrou novos focos de lesão isquémica (no centro semioval, na corona radiata, na cabeça do caudado ipsilaterais, e no centro semioval frontal esquerdo), provavelmente de etiologia cardio-embólica em contexto de endocardite (Fig. 2).

Ao $27^{\circ}$ dia de internamento, repete ecocardiograma transtorácico que revela insuficiência mitral por perfuração do folheto posterior - quantificada em grau severo (PSAP 75 mmHg), confirmada por ecocardiograma transesofágico. Foi contactado o serviço de cirurgia cardiotorácica do Hospital de São João que, tendo em conta a idade, comobilidades do doente e a evolução favorável da infeção, considerou que o doente não tinha indicação para cirurgia.

O doente completou um total de 6 semanas de antibioterapia. Manteve-se hemodinamicamente estável e em apirexia. Foi elaborado um plano de reabilitação pela medicina física e reabilitação e o doente foi admitido na

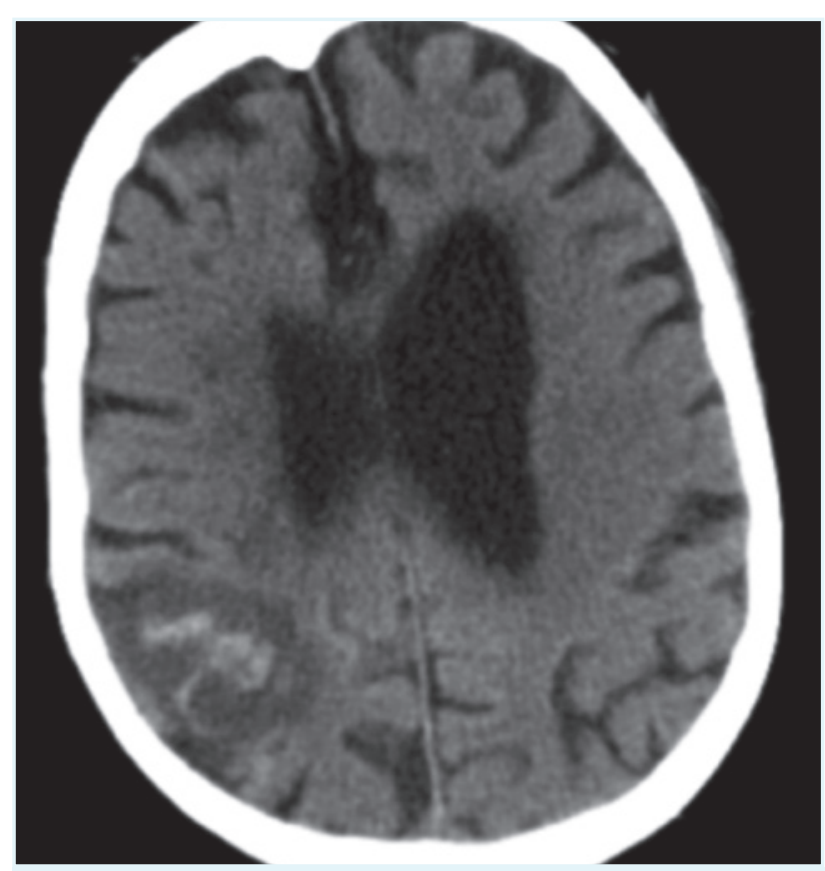

FIGURA 1. Lesão isquémica com hemorragia associada.

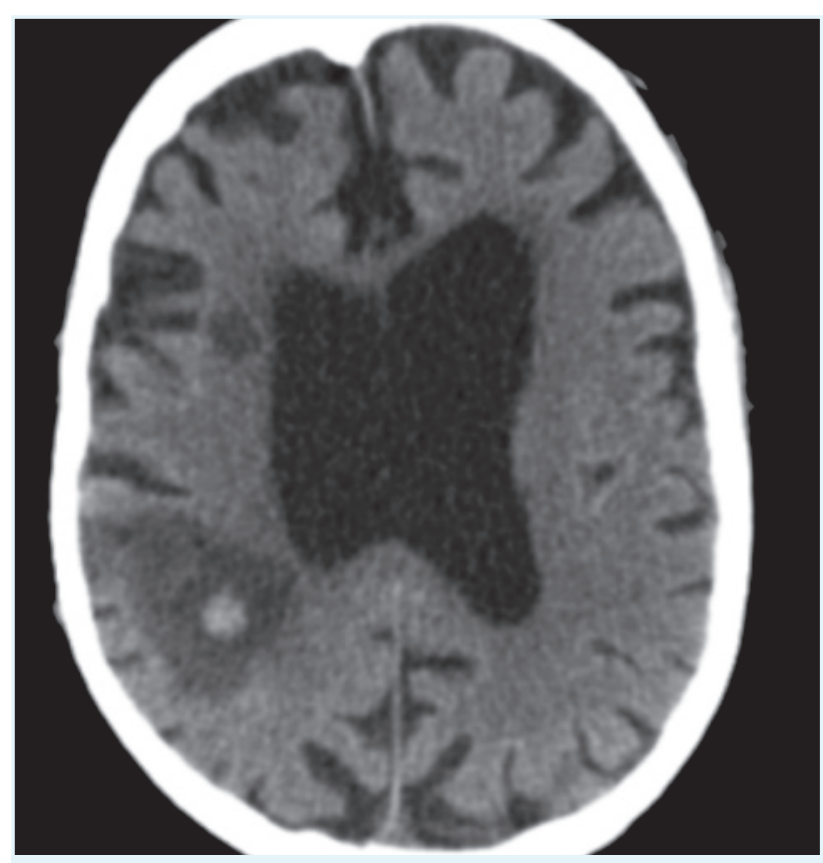

FIGURA 2. Lesão isquémica parietal direita de novo 3 dias após o episódio.

TABELA 3. Evolução de parâmetros inflamatórios e creatinina ao longo do internamento.

\begin{tabular}{|l|c|c|c|c|c|c|c|c|c|}
\hline & D1 & D4 & D7 & D9 & D12 & D14 & D18 & D22 & D35 \\
\hline PCR & 194 & 161 & 81,8 & 69 & 92 & 91,7 & 35,5 & 29,1 & 28,2 \\
\hline $\begin{array}{l}\text { Procalcito- } \\
\text { nina }\end{array}$ & & 68,4 & 12,5 & 3,1 & & & & & \\
\hline $\begin{array}{l}\text { Leucócitos } \\
\text { Creatinina }\end{array}$ & 25,4 & 14,8 & 15,1 & 12,2 & 14,4 & 13,8 & 7,1 & 8,3 & 8,2 \\
\hline
\end{tabular}

PCR - proteína C reativa; D - dia.

Valores de Referência: PCR < 3 mg/L; Procalcitonina < 0,5 ng/mL - baixo risco de sépsis, > 2,0 ng/mL - risco elevado de sépsis; Leucócitos 4,0 - 11,0 × 10³/uL; Creatinina 0,5 - 1,2 mg/dL. 
rede nacional de cuidados continuados ao fim de 59 dias de internamento. Faleceu 4 meses após a alta hospitalar.

\section{DISCUSSÃO}

E. coli é o micro-organismo mais vezes associado a infeção do trato urinário. A bacteriemia por E. coli é uma complicação relativamente comum, no entanto, a endocardite por este patogénico é rara. Esta baixa incidência deve-se essencialmente à incapacidade desta bactéria aderir ao endocárdio e ao facto de o soro humano conter anticorpos contra a E. coli. ${ }^{3}$ Num estudo onde foram analisados 3605 casos de bacteriemia, a E. coli foi responsável por 23,9\% dos casos, e apenas ocorreu endocardite em 0,05\% dos casos. ${ }^{4}$ Numa revisão sobre todos os casos da literatura de endocardite por E. coli entre 1909 e 2002, apenas foram encontrados 36 casos, sendo mais frequente em mulheres idosas imunocomprometidas. ${ }^{5}$ Na realidade, verificamos que as bactérias Gram-negativas (onde se inclui a E. coli) são menos sensíveis à lise mediada pelo complemento e pela imunidade humoral uma vez que não possuem proteínas de superfície. Este facto também contribui para a baixa probabilidade de constituírem os agentes etiológicos de endocardite, uma vez que são estas proteínas de superfície que permitem a sua adesão as moléculas de matriz e material protésico. ${ }^{6}$ Por outro lado, as bactérias Gram-negativas apresentam alguns fatores de virulência que os tornam sérios patogénios, como sejam as adesinas, o sistema de aquisição de ferro e a capacidade de produzir toxinas, permitindo o acesso da bactéria a locais usualmente estéreis. ${ }^{6}$ A endocardite por bactérias Gram-negativas está associada a uma alta taxa de mortalidade e morbilidade, requerendo por isso uma terapia médica agressiva e cirúrgica precoce. A taxa de mortalidade varia entre 30\% - 83\% nas diferentes series. ${ }^{7}$

O doente apresentado satisfazia um critério major e três critérios minor para o diagnóstico clínico de endocardite infeciosa definitiva, segundos os critérios de Duke modificados. 8 doente não apresentava história de doença valvular (apenas insuficiência cardíaca de provável etiologia hipertensiva) ou de consumos de drogas ilícitas, nem patologia renal, manipulações ou infeções recorrentes do trato urinário. A etiologia mais provável da bacteriemia foi o trato urinário. À admissão o doente apresentava ainda critérios de sépsis severa (temperatura superior a $38^{\circ} \mathrm{C}$, contagem leucocitária superior a 12,000 u/L e hipotensão).

O diagnóstico diferencial de uma febre persistente em qualquer doente com septicemia após antibioterapia dirigida à cultura inclui a endocardite infeciosa, sobreinfe- ção por fungos ou outra bactéria resistente ao antibiótico em curso, presença de abcesso, eventos embólicos ou um foco metastático. ${ }^{2,8}$ No caso apresentado, para além da persistência da febre o doente apresentou um sopro cardíaco de novo, que alertou a equipa clínica para a possibilidade de endocardite.

\section{CONCLUSÃO}

A endocardite infeciosa, estando frequentemente associada a complicações graves, obriga a internamento muito prolongado e mantém-se ainda uma entidade com elevada morbi-mortalidade, apesar dos avanços técnicos e terapêuticos da medicina. Este caso ilustra a necessidade de estabelecer diagnósticos diferenciais em doentes com urosepsis e febre persistente apesar do tratamento antibiótico adequado.

A antibioterapia agressiva e o tratamento cirúrgico são de vital importância para aumentar a sobrevivência destes doentes.

CONFLITOS DE INTERESSE: Os autores declaram não ter qualquer conflito de interesse na realização do presente trabalho.

FONTES DE FINANCIAMENTO: Não houve qualquer fonte de financiamento na realização do presente trabalho.

CONFIDENCIALIDADE DOS DADOS: Os autores declaram ter seguido os protocolos da sua instituição acerca da publicação dos dados de doentes.

PROTEÇÃO DE PESSOAS E ANIMAIS: Os autores declaram que os procedimentos seguidos na elaboração do presente trabalho estão em conformidade com as normas das comissões de investigação clínica e de ética, bem como da declaração de Helsínquia e da Associação Médica Mundial.

CONFLICTS OF INTEREST: The authors declare that they have no conflicts of interest.

FINANCIAL SUPPORT: This work has not received any contribution, grant or scholarship.

CONFIDENTIALITY OF DATA: The authors declare that they have followed the protocols of their work center on the publication of data from patients.

PROTECTION OF HUMAN AND ANIMAL SUBJECTS: The authors declare that the procedures followed were in accordance with the regulations of the relevant clinical research ethics committee and with those of the Code of Ethics of the World Medical Association (Declaration of Helsinki). 


\section{REFERÊNCIAS}

1. Cabell C, Abrutyn E, Karchmer A. Bacterial endocarditis the disease, treatment, and prevention. Circulation. 2003;107: e185-e187.

2. Rangarajan D, Ramakrishnan S, Patro K, Devaraj S, Krishnamurthy V, Kothari Y, et al. Native valve Escherichia coli endocarditis following urosepsis. Indian J Nephrol. 2013; 23:232-4. doi: 10.4103/0971-4065.111866.

3. Watanakunakorn C, Burket T. Infective endocarditis in a large community teaching hospital 1980-1990. A review of 210 episodes. Medicine. 1993;72:90-102.

4. Gransden W, Eykyn S, Phillips I, Rowe B. Bacteremia due to Escherichia coli: a study of 861 episodes. Rev Infect Dis. 1990;12:1008-18.

5. Micol R, Lortholary O, Jaureguy F, Bonacorsi S, Bingen E, Lefort A, et al. Escherichia coli native valve endocarditis. Clin Microbiol Infect. 2006;12:401-3. doi: 10.1111/j. 1469-0691.2006.01375.x.

6. Russo T, Johnson J. Proposal for a new inclusive definition for extraintestinal pathogenic isolates of Escherichia coli: ExPEC. J Infect Dis. 2000;181:1753-4.

7. Morpeth S, Murdoch D, Cabell CH, Karchmer AW, Pappas P, Levine D, et al. Non-HACEK gram-negative bacillus endocarditis. Ann Intern Med. 2007;147:829-35.

8. Baddour L, Wilson W, Bayer A, Fowler V, Bolger A, Levison M, et al. Infective endocarditis diagnosis, antimicrobial therapy, and management of complications. Circulation. 2005;111:e394434. 